\title{
Estudos epistemológicos em política educacional ${ }^{1}$
}

\section{Altair Alberto Fávero*}

A coletânea Estudos epistemológicos no campo da pesquisa em política educacional tem por escopo interpelar os modos de produção de conhecimento em política educativa. Organizada em duas partes, a primeira delas intitulada "Perspectivas epistemológicas para a análise de políticas educativas" e a segunda intitulada "Perspectivas epistemetodológicas para a análise das políticas educativas", a obra visa a atualizar o debate teórico que realizam alguns investigadores para compreender e fortalecer as pesquisas nesse campo do conhecimento.

Nos textos que compõem essa coletânea, observa-se como as diferentes perspectivas podem vir a contribuir para fortalecer o campo da investigação em políticas educacionais. Os capítulos apresentados desenvolvem uma perspectiva epistemológica e epistemetodológica congruente e sólida a partir das investigações em políticas educativas. Por essa razão, foram mapeadas algumas perspectivas e enfoques epistemetodológicos, mostrando que é possível, mediante o uso de diversos autores, sustentar um referencial teórico com potencialidade conceitual que nos permita compreender a realidade educativa dinâmica e transformadora.Mesmo nos casos onde se vinculam correntes teóricas que pertencem a distintas perspectivas epistemológicas, os estudos epistemológicos tornam possível realizar um quadro conceitual sólido, pois possibilitam conhecer e aplicar os referenciais com profundidade. Assim, o Enfoque da Epistemologia da Política Educativa (EEPE) permite construir referenciais e marcos teóricos apropriados para a investigação, contribuindo para uma tomada de consciência da tarefa de um pesquisador.

A principal dificuldade que se pode observar nos estudantes é o momento de construir um projeto de investigação em educação delimitando o objeto de estudos. Não podemos deixar de afirmar que existe uma carência de trabalhos científicos que analisam esse aspecto central de construção do objeto de pesquisa. O conhecimento apresenta-se como uma ferramenta de múltiplos usos políticos, tendo tanto o caráter político estratégico ou libertário quanto o de mercadoria, no sentido de

Recebido: 02/09/2013 - Aprovado: 28/11/2013

http://dx.doi.org/10.5335/rep.v21i1.3882

Possui pós-doutorado (Bolsista Capes) pela Universidad Autónoma del Estado de México (UAEMéx) e doutorado em Educação pela UFRGS. Professor e pesquisador no curso de Filosofia e no programa de Pós-graduação em Educação na Universidade de Passo Fundo. E-mail: altairfavero@gmail.com. 
fazer-se valer dos interesses econômicos dos capitalistas. O poder emancipatório, em sua capacidade de incrementar o diálogo e as possibilidades de ação da coletividade, passaria pela ideia de que, ao mesmo tempo em que deve romper com o senso comum, no sentido de desenvolver-se analítica e formalmente, a ciência deve retornar ao senso comum enquanto disponibilidade e acessibilidade, ainda que seu registro formal deva ser traduzido para uma linguagem mais funcional.

Mas há quem pense que, ao servir aos interesses imediatos dos dominantes, a Educação tenderia, em médio ou longo prazo, ou, ainda, de modo indireto, a favorecer toda a comunidade, pois o desenvolvimento social, em seus mais variados aspectos, passaria pelo incremento das privatizações. Essa visão traz em si o preconceito de que apenas a escola privada seria uma instância de auto-organização, capaz de agenciar saber e promover benefícios comuns. Assim, a diferenciação de público e privado seria meramente formal, pois, na prática, o agente do bem público não seria o governo, tampouco entidades não lucrativas, quer dizer, auto-organizacionais, cooperativas, nem no sentido puro, nem no misto, ou seja, que combinam benefícios imediatos em termos de melhorias do nível de vida dos seus participantes, e, ainda, com fins lucrativos.

Os textos que compõem a coletânea na sua globalidade apresentam um debate atual de recente constituição, como é o campo dos estudos epistemológicos de pesquisas em política educacional. Esse enfoque não deve assumir-se, como afirmam os organizadores, "como um instrumento prescritivo para 'saber' como se deve pesquisar em política educacional, pelo contrário, é um esquema flexível que intenta promover, por meio de componentes, a reflexividade sobre os processos de pesquisa do campo da política educacional [...]” (p. 13).

É necessário, portanto, que a pesquisa científica seja repensada para que consiga fazer a diferença nessa sociedade inserida em um mercado econômico que tem como base o capitalismo, a fim de que possa transformar a informação em conhecimento socialmente significativo para a maioria da população.

O que temos é que a ciência, enquanto atividade humana, não pode renegar seu caráter histórico de práxis libertadora ou de alienação utilitária, em que estaria a serviço da acumulação do capital. A ideia de "ciência una" possibilita-nos pensar as atividades científicas das mais diversas "especialidades" como um fazer integrado historicamente, quer para maximizar os lucros do capital, quer para contribuir em termos de liberar o "gênero humano", que, nas condições atuais do capitalismo, significaria contribuir no sentido da luta pela emancipação da classe trabalhadora.

O Enfoque das Epistemologias da Política Educativa (EEPE) e as reflexões que surgem da tarefa de pesquisa em política educacional fortalecem o campo de investigação e possibilitam o surgimento do campo de estudos epistemológicos em política educativa. Com efeito, os organizadores da coletânea empregam a categoria 
"Epistemologias" no plural, "dado que existem diversos posicionamentos e perspectivas epistemológicas para desenvolver e levar a cabo uma investigação em política educativa, isto é: existem diversas epistemologias de política educativa" (p. 13).

Em síntese, a questão que se apresenta não é se a pesquisa e a projeção social que realizam as ciências humanas e sociais contêm ou não valores e ideologias, mas, sim, quais são os valores que se encontram em cada processo e situação, qual é seu papel e como as diferentes visões de realidade fazem-se explícitas no processo de pesquisa.

Os organizadores alertam, na apresentação da coletânea, que "não devemos confundir temáticas de estudos em política educativa com os posicionamentos epistemológicos ou perspectivas epistemológicas", pois "os estudos sobre", por si só, "não são perspectivas epistemológicas e nem trazem por si posicionamento epistemológico" (p. 15).

Os capítulos com compõe a coletânea estão organizados da seguinte forma: No primeiro capítulo, intitulado "A perspectiva epistemológica de Gramsci e a pesquisa de políticas educacionais", Maria de Lurdes Pinto de Almeida e Sidney Reinaldo da Silva mostram de que forma Gramsci reapropriou-se do marxismo como "filosofia da práxis" e de que forma isso se constitui "um posicionamento epistemológico" (p. 27).

No capítulo "Orientações para o desenvolvimento de investigação em políticas educativas a partir da teoria marxista", Gisele Masson reconhece que "as políticas educativas na América Latina ainda é [sic] um campo em construção” (p. 56) e que, nos últimos anos, "a pesquisa sobre políticas educacionais está se expandindo" (p. 56), embora permaneça "a necessidade do aprofundamento dos estudos em relação ao referencial teórico adotado" (p. 57). Nesse sentido, o capítulo procura "destacar as questões fundamentais da teoria marxista que podem contribuir para uma maior consistência analítica nas investigações educativas que adotam tal teoria" (p. 71).

No capítulo intitulado "Superando limites disciplinares e territoriais: a ruptura epistemológica de Roger Dale na pesquisa em política educativa”, os autores Xavier Bonal, Aina Tarabini e Antoni Verger ressaltam a centralidade da expressão "ruptura" nas investigações da sociologia da educação de Roger Dale. O texto apresenta as principais dimensões da ruptura epistemológica desse importante autor “como marco explicativo das relações entre educação política e sociedade" (p. 78).

No capítulo "A perspectiva epistemológica de Pierre Bourdieu: as apropriações no campo acadêmico", Nicolás José Isola e Hermán Mariano Amar descrevem e analisam a noção de "campos científicos" no pensamento de Pierre Bourdieu. Tal descrição e análise serviram de base para os atores indicarem as apropriações intelectuais do sociólogo francês nos projetos de desenvolvimento e educação na América Latina e no Caribe. No final do capítulo (p. 126-134), Isola e Amar mostram 
de que forma se dá a passagem da teoria de Bourdieu para a planificação de certas políticas nacionais na Argentina no período de 1983-1989.

No capítulo cinco, intitulado "A abordagem do ciclo de políticas como epistemologia" Jefferson Mainardes e Luís Armando Gandin apresentam "as principais características da abordagem do ciclo de políticas enquanto um enfoque epistemológico, a utilização dessa abordagem no Brasil, as potencialidades da referida abordagem para a pesquisa sobre políticas educacionais e alguns questionamentos que têm sido feitos a esta abordagem" (p. 143).

No sexto capítulo, os pesquisadores argentinos César Tello e Jorge Gorostiaga descrevem "o enfoque metodológico da Cartografia Social (CS) baseado em uma epistemologia visual como uma possibilidade para levar a cabo processos de investigação em política educativa" (p. 169). A cartografia social é definida pelos autores, na tradição criada por Rolland Paulston, como "um enfoque metodológico baseado na análise textual que busca a representação de fenômenos socioeducativos por meio de mapas que reinscrevem e estruturam uma multiplicidade de perspectivas ou formas de ver esses fenômenos" (p. 170). Além de apresentarem os pilares da cartografia social no enfoque metodológico e os antecedentes dos conceitos de produção de conhecimento em relação ao visual, os autores expõem os aspectos metodológicos para a construção de mapas, desde a cartografia social, e ilustram os resultados de uma investigação sobre globalização e reformas educativas na América Latina.

No sétimo capítulo, Renata Giovine e Juan Suásnabar fazem uma "descrição das contribuições do neoinstitucionalismo para o campo das políticas educacionais" (p. 196), realizam uma "análise de políticas para o estudo dos textos legais na área educacional" (p. 203) e, por fim, apresentam a "Análise Política do Discurso" com "uma corrente epistemológica utilizada para abordar os fenômenos sociais e educacionais que se desenvolveram nas últimas décadas na América Latina e na Argentina" (p. 204).

A coletânea é encerrada com um "Posfácio" escrito pelos próprios organizadores, onde destacam que "as diferentes perspectivas [apresentadas nos diversos textos que a compõem] podem vir a contribuir para fortalecer o campo da investigação em políticas educacionais sempre, quando [...] estes desenvolvem uma perspectiva epistemológica e epistemetodológica que sejam congruentes e sólidas [sic] a partir das investigações em políticas educativas [...]” (p. 232). Os organizadores acreditam "que [isso] é possível, usando diversos autores, sustentando um referencial teórico com potencialidade conceitual que nos permita compreender a realidade educativa dinâmica e transformadora" (p. 232).

Certamente, a coletânea constitui uma leitura obrigatória para todos os que estudam Políticas Educacionais, além de objeto de investigação aos pesquisadores que estão se debruçando sobre as problemáticas investigativas que tratam do tipo de 
conhecimento produzido no campo em pauta. Por ser um assunto recente e por não existir uma quantidade suficiente de estudos situados nesse campo, a temática central que perpassa toda a coletânea vem a somar e multiplicar a discussão no âmbito da pós-graduação e nos diversos grupos de pesquisa do Brasil e da América Latina.

\section{Notas}

1 Resenha: TELLO, Cesar; ALMEIDA, Maria de Lourdes Pinto de Almeida (Orgs.). Estudos epistemológicos no campo da pesquisa em política educacional. Campinas, SP: Mercado de Letras, 2013. 